\title{
Düşük güçte bir motor test düzeneği kurulumu ve örnek bir uygulama gerçekleştirilmesi
}

\author{
Mehmet AKÇAY ${ }^{1}$, Salih ÖZER ${ }^{1 *}$, İlker Turgut YILMAZ ${ }^{2}$, Erdinç VURAL ${ }^{3}$ \\ ${ }^{1}$ Muş Alparslan Üniversitesi, Mühendislik-Mimarlık Fakültesi, Muş, Türkiye \\ ${ }^{2}$ Ístanbul Marmara Üniversitesi, Teknoloji Fakültesi, İstanbul, Türkiye \\ ${ }^{3}$ Aydın Adnan Menderes Üniversitesi, Germencik Meslek Yüksek Okulu, Aydın, Türkiye \\ (ORCID:0000-0002-6968-8734) (ORCID:0000-0002-5030-1296) \\ (ORCID:0000-0002-0398-7635) (ORCID:0000-0002-8018-2064)
}

\begin{abstract}
$\ddot{\mathbf{O z}}$
İçten yanmalı motorların test edilmesi işleminde genellikle ithalat yoluyla temin edilen, oldukça yüksek maliyetli motor test dinamometreleri kullanılmaktadır. Bu çalışmanın amacı, oldukça yüksek maliyetli olan içten yanmalı motor test dinamometreleri yerine, tek silindirli dizel motorlu bir jeneratörün motor test düzeneğine dönüştürülmesi ile düşük maliyetli bir içten yanmalı motor test düzeneği elde etmektir. Elde edilen düzenekte viskozitesi toluen ile iyileştirilmiş olan fuel-oil kullanılarak motor performansına etkileri incelenmiştir. Bu çalışma kapsamında $10 \mathrm{HP}$ güce ve $3000 \mathrm{~d} / \mathrm{d}$ sabit devire sahip dizel motorlu jeneratör kullanılmıştır. Dizel motorun yüklenmesi işlemi jeneratöre alıcı bağlanması ile gerçekleştirilmiştir. Motorun gücü ve her bir krank mili açısı için silindir içi basıncı, yakıt hattı basıncı anlık olarak gözlenmiş ve kaydedilmiştir. Dizel ve dizel+fuel-oil karışımları kullanılarak gerçekleştirilen deneylerde, fuel-oil katkısı ile silindir içi basınç değerinin düştüğü, yakıt tüketiminin ve egzoz gazı sıcaklığının arttığı görülmüştür.
\end{abstract}

Anahtar kelimeler: Motor Dinamometresi, Alternatif Yakıt, Fuel-oil, Motor Performansı.

\section{Designing a low power motor test assembly and performing a sample application}

\begin{abstract}
In the process of testing the internal combustion engines, high-cost engine test dynamometers are generally used. The aim of this study is to obtain a low-cost internal combustion engine tester by converting a single-cylinder diesel engine generator into a motor tester, rather than a high-cost internal combustion engine test dynamometer. Engine performance effects were investigated by using fuel-oil with viscosity toluene. Within the scope of this study, diesel powered generator with $10 \mathrm{HP}$ power and $3000 \mathrm{1} / \mathrm{min}$ constant speed is used. The loading of the diesel engine was carried out by connecting the receiver to the generator. The in-cylinder pressure for the engine power and the crankshaft angle was instantaneously monitored and recorded at the fuel line pressure. In experiments carried out using diesel and diesel + fuel-oil mixtures, with the addition of fuel-oil, it was seen that the pressure in the cylinder decreased and fuel consumption and exhaust gas temperature increased.
\end{abstract}

Keywords: Engine Dynamometer, Alternative Fuel, Fuel-oil, Engine Performance.

\section{Giriş}

İçten yanmalı motorların birçok sınıflandırılma şekli vardır. Bunlardan bir tanesi de ürettikleri güçlere göre olan sınıflandırılma şeklidir. Buna göre, üretilen veya geliştirilen motorlardan elde edilen gücün ölçülmesi gerekmektedir. Bir içten yanmalı motorun taşıt üzerinde iken karşılaştığı çalışma koşulları, araç olmadan bir motor test tezgahında simülasyon edilebilmektedir. Yük koşulları, test tezgâhı üzerinde motorun krank miline bağlı bir dinamometre ile uygulanmaktadır. Test tezgahı ile yapılan çalışmada, sıcaklık ve basınç gibi tekrarlanabilir koşulları sabit tutulabilmekte, geliştirme ve konfigürasyon için

*Sorumlu yazar: s.ozer@alparslan.edu.tr

Geliş Tarihi: 21.05.2019, Kabul Tarihi: 23.09.2019 
gereken maliyetler ve zaman azaltılabilmektedir [1,2]. İçten yanmalı motorların test edilme işlemi için birçok farklı türü bulunan motor dinamometreleri kullanılmaktadır [3]. Motor çıkış milinin dönme hızını ve motor tarafindan şafta uygulanan mekanik kuvveti bir fren yükü uygulayarak ölçen cihazlara dinamometre denilmektedir [4].

Motor dinamometreleri, genel olarak hidrolik ve elektrikli olarak sinıflandırılmakta olup [5] elektrikli dinamometreler daha hassas ölçüm işlemi ve hızlı test edebilme özelliklerinden dolayı hidrolik dinamometrelere göre daha çok tercih edilmektedirler [6]. Elektrik dinamometreleri, motordan emilen gücü elektrik enerjisine dönüştürmekte ve daha sonra bu elektrik enerjisi 1sıya dönüştürülerek su veya havaya atılmaktadır [4]. Yine benzer şekilde test edilecek motorun mili doğrudan bir jeneratöre bağlandığında, motorun ürettiği güç jeneratör tarafından elektrik enerjisine dönüştürülmekte, elde edilen elektrik enerjisi dirençler vasıtasıyla ısıya dönüştürülerek harcanmaktadır. Jeneratör tarafından üretilen güç, yükleme sırasında dirençlere uygulanan gerilim ve akım ölçülerek belirlenmektedir. Devreye sokulan direnç sayısının kontrolü ile motora uygulanacak olan yük ayarlanabilmektedir [7].

Literatürde, motor performans deneylerinin gerçekleştirilmesi amaciyla jeneratörlerin kullanıldığı birçok çalışma mevcuttur. Bunlardan bazıları aşağıda kısaca özetlenmeye çalışılmıştır. Oliveira ve ark. (2017) B7 yakıtı (\% 7 biyodizel+\%93 dizel karışımı) ile \% 5 ile \% 30 arasında değişen konsantrasyonlarda sulu etanol karışımının motor performans ve emisyonları üzerine etkisini inceledikleri çalışmada, $49 \mathrm{~kW}$ gücünde dizel jeneratör kullanmışlardır [8]. Işık ve ark. (2017), nbütanol katkısının biyodizel-dizel karışımının yanma, performans ve emisyonları üzerine etkisini araştırdıkları deneysel çalışmada, 4 silindirli, 4 zamanlı, direk enjeksiyonlu ve su soğutmalı $18 \mathrm{~kW}$ gücünde dizel motor jeneratörü kullanmışlardır. Dizel jeneratörünün yüklenmesi işleminde değişken dirençli ısıtıcı rezistans ünitesi kullanılmıştır [9]. Late ve ark. (2012), dizel bir jeneratörde hidrojen ve LPG ilavesinin motora etkilerini incelemişlerdir. Motorun değişik yük kademelerinde yüklenmesi için su pompası ve endüstriyel isıtıcılar kullanılmıştır [10]. Sing ve ark. (2007), tarafından yapılan deneysel çalışmada, üç silindirli bir dizel motoru sabit devir elektrik üretecine bağlamış ve alternatif yakıt karışımları ile ürettiği gücün ne kadarlık bir değişim ile üretildiğini araştırmışlardır [11].

Elektrikli dinamometreye sahip test standartlarının fiyatları oldukça yüksektir ve genellikle yurt dışından temin edilmektedirler [6]. Dolayısıyla yerli kaynaklar kullanılarak daha ekonomik motor test standı imalatının gerçekleştirilmesi ve yaygınlaştırılması, bu alanda yapılan çalışmaların daha düşük maliyetler ile gerçekleştirilebilmesine imkân sağlayacağı açıktır. Yapılan literatür araştırmasında da görüldüğg̈ üzere, jeneratörlerin ilave aparatlarla yüklenmesi ile motor testleri yapılabilmektedir. $\mathrm{Bu}$ çalışmada da maksimum çalışma gücü $7 \mathrm{~kW}$ olan alternatöre sahip dizel jeneratör tercih edilmiştir. $\mathrm{Bu}$ jeneratörün motoru ise 4 zamanl1, hava soğutmalı, direk enjeksiyonlu $10 \mathrm{HP}$ gücündedir. Motorun yüklenmesi işlemi için deney düzeneğine $250 \mathrm{~W}$ ve $1000 \mathrm{~W}^{\prime} l$ lk projektörler ile yükleme ünitesi kurulmuştur. Motor üzerinde yapılan değişiklikler ile motorun silindir içi basınç, yakıt hat basıncı, motor devri ve egzoz gazı sıcaklığı değerleri ölçülmüş ve yüksek frekanslı dijital osilaskop ile kayıt altına alınarak veriler değerlendirilmiştir.

\section{Motor test düzeneğinin kurulumu}

Bu bölümde, düşük güçte bir motor test düzeneğinin oluşturulması amacıyla, dizel motorlu jeneratörün üzerinde yapılan değişiklikler ve dizel motoruna ilave edilen parçalar ile ilgili detaylı bilgi sunulmaktadır. Tablo 1'de jeneratörün teknik özellikleri verilmektedir.

Tablo 1. GENPOWER GDG 7000 jeneratörünün teknik özellikleri.

\begin{tabular}{lc}
\hline & Motor \\
\hline Model & 186 FAG \\
Tip & Hava Soğutmalı- 4 Zamanlı \\
Silindir Hacmi & $418 \mathrm{~cm}^{3}$ \\
Maksimum Çıkı̧̧ gücü & $7 \mathrm{~kW}$ \\
Çalıştırma Şekli & Marşlı \\
\hline \multicolumn{2}{c}{ Jeneräör } \\
\hline Maksimum Çıkış Gücü & $7 \mathrm{kVA}$ \\
Sürekli Çalışma Gücü & $6 \mathrm{kVA}$ \\
Frekans & $50 \mathrm{~Hz}$ \\
\hline
\end{tabular}




\subsection{Deney motorunun yüklenmesi}

Dizel motorunun yüklenmesi işlemi, jeneratörün çektiği akımın kontrol edilmesi ile sağlanmaktadır. Bu amaçla $250 \mathrm{~W}$ ve $1000 \mathrm{~W}$ gücünde metal halide ampüllü projektörler kullanılmış ve jeneratörden çekilen güç kontrol edilerek dizel motorunun yüklenmesi işlemi gerçekleştirilmiştir. Dizel motoru $7 \mathrm{~kW}$ gücündedir. Dolayısıyla jeneratöre bağlanan 7 adet $1000 \mathrm{~W}$ gücündeki projektör ile dizel motorunun tam yükte yüklenmesi sağlanmaktadır. Her bir projektöre farklı güçte yükleme işlemi için ayrı ayrı anahtar devreleri kurulmuş ve jeneratör ile elektrik bağlantıları 3x2,5 elektrik kabloları kullanılarak gerçekleştirilmiştir. Literatürde deney motorunun yüklenmesi işleminde benzer uygulamalara rastlamak mümkündür [5,12]. Şekil 1'de deney düzeneğinin yükleme ünitesinde kullanılan $250 \mathrm{~W}$ ve $1000 \mathrm{~W}$ projektörler ve montaj yapılmış hali görülmektedir.

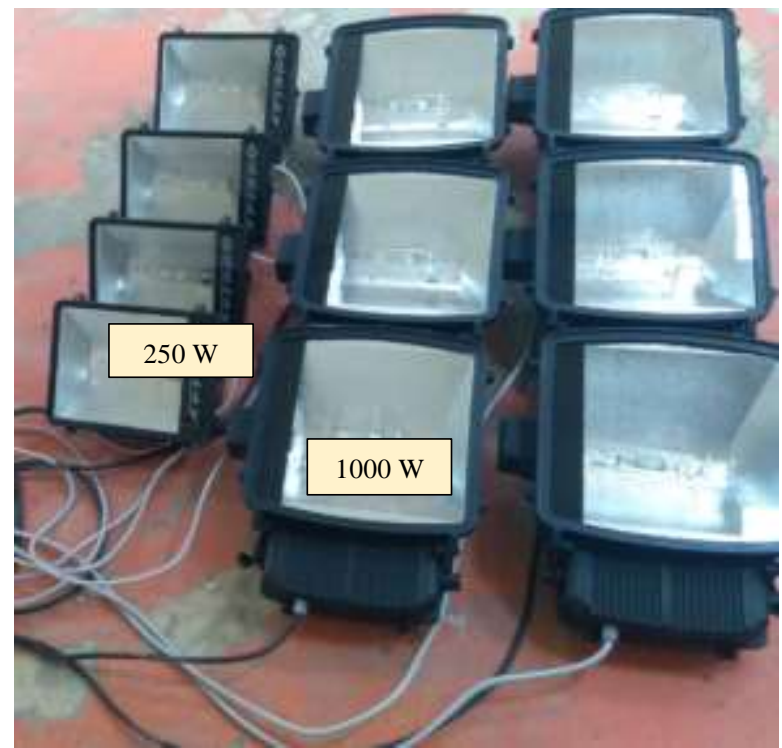

Şekil 1. Deney düzeneğinin yükleme ünitesinde kullanılan projektörlerin montaj yapılmış hali

\subsection{Silindir içi basınç ölçümü}

Silindir içi basıncın anlık ölçülmesi amacıyla bir adet KİSTLER marka silindir içi basınç sensörü ve bir adet de sensör yükselticisi kullanılmıştır. İçten yanmalı motorlar üzerine yapılan çalışmalarda silindir içi basıncın ölçülmesi işleminde KİSTLER Piezo dirençli sensörlerin kullanıldığı birçok çalışma mevcuttur [13-16]. Silindir içi basınç sensörünün özellikleri Tablo 2'de verilmiştir.

Tablo 2. Kistler 4065B0200DS1-2,0 silindir içi basınç sensörü özellikleri

\begin{tabular}{|c|c|c|c|c|}
\hline Model & & $\begin{array}{l}\text { Kistler Piezo } \\
\text { Basınç Sensörü }\end{array}$ & Dirençli & Mutlak \\
\hline Ölçüm aralığ1 & bar & $0-200$ & & \\
\hline Aşırı yükleme & bar & 300 & & \\
\hline Besleme gerilimi (Amplifikatör) & $\mathrm{V} \mathrm{DC}$ & $10-30$ & & \\
\hline Çıkış voltajı & V DC & $0-5( \pm 0,025)$ & & \\
\hline Frekans & $\mathrm{kHz}$ & $0-40$ & & \\
\hline Maksimum sapma basıncı & $\%$ & \pm 1.5 & & \\
\hline Lineerlik & $\%$ & $\leq \pm 0.3$ & & \\
\hline Çalışma sıcaklığ & ${ }^{\circ} \mathrm{C}$ & $-40-+140$ & & \\
\hline
\end{tabular}

Silindir içi basınç sensörünün montaj işlemi için öncelikle dizel motorun silindir kapağı üzerine M6 matkap ile delik delinmiştir. Daha sonra bu deliğin içerisine $\mathrm{M} 7 \mathrm{x} 0,75$ diş açılarak silindir içi basınç sensörünün montaj1 gerçekleştirilmiştir. Şekil 2'de basınç sensörünün montaj1 için silindir kapağına açılan delik ve sensörün montajlı hali görülmektedir. 


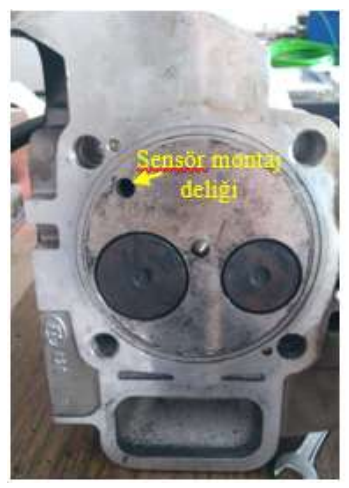

a) Silindir kapağ

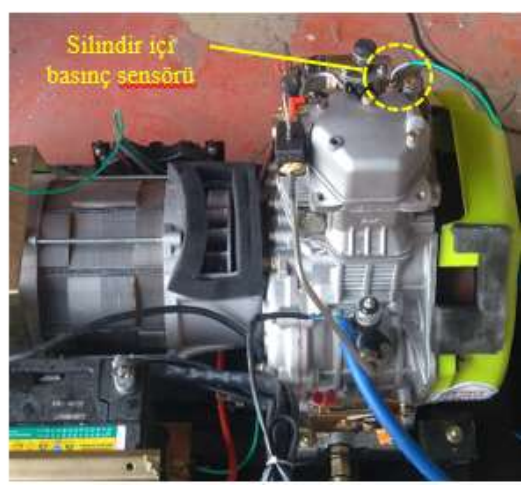

b) Silindir içi basınç sensörünün montajlı hali

Şekil 2. Silindir içi basınç sensörünün deney motoruna montajı

\subsection{Yakıt hattı basınç ölçümü}

Dizel motorunun yakıt hattı basıncının anlık olarak ölçülmesi amacıyla bir adet OPRANT marka basınç sensörü kullanılmıştır. Literatürde dizel motorlarında yakıt hat basıncının ölçülmesi işleminde Oprant AutoPSI Basınç Sensörünün kullanıldığı çalışmalara rastlamak mümkündür [17]. Yakıt hattı basınç sensörünün özellikleri Tablo 3'de verilmiştir.

Tablo 3. Oprant AutoPSI basinç sensörü özellikleri

\begin{tabular}{lcl}
\hline Model & & Oprant AutoPSI Basınç Sensoru \\
\hline Ölçüm aralığı & bar & $0-340$ \\
Aşırı yükleme & bar & 680 \\
Giriş voltajı & V DC & $9-18$ \\
Çıkış voltajı & V DC & $0,5-5$ \\
Frekans & $\mathrm{kHz}$ & $0,1-20$ \\
Hassasiyet & $\%$ & \pm 1 yanma şartlarında \\
Sensör çalışma sıcaklığı & $\%$ & $\pm 0,5$ yanma olmadığında \\
\hline
\end{tabular}

Yakıt hattı basınç sensörünün montajını gerçekleştirebilmek için öncelikle çelik malzemeden bir ara bağlantı parçası imal edilmiştir. Ara bağlantı parçasına gerekli ölçülerde delikler açılarak yakıt hat basınç sensörünün montajı gerçekleştirilmiştir. Yakıt hattı borusu motor üzerinden sökülmüş ve yakıt enjektörüne mümkün olduğunca yakın bir bölümünden kesilerek ikiye ayrılmıştır. Yakıt hattı boyunun uzamasından kaynaklanabilecek ateşleme gecikmesi ve benzeri olumsuzlukların önüne geçmek amacıyla ara bağlantı parçasının genişliği kadar yakıt hattı borusundan kesilerek yakıt borusunun boyu kısaltılmıştır. İki parçalı bakır alaşımlı yakıt hattı borusunun arasına, imalatı yapılmış olan ara bağlantı parçası yerleştirilerek kaynaklı birleştirme işlemi ile birleştirilmiştir. Şekil 3'de yakıt hattı basınç sensörünün montajı için imal edilen ara bağlantı parçası ve yakıt hattı borusuna montajı görülmektedir.

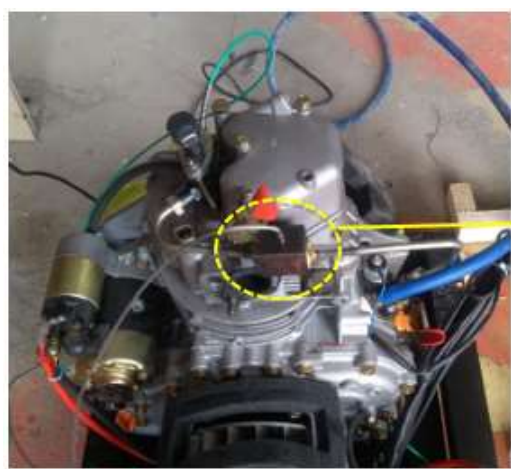

a) Yakıt hattı basınç sensörü ara bağlantı parçası montajının genel görünümü

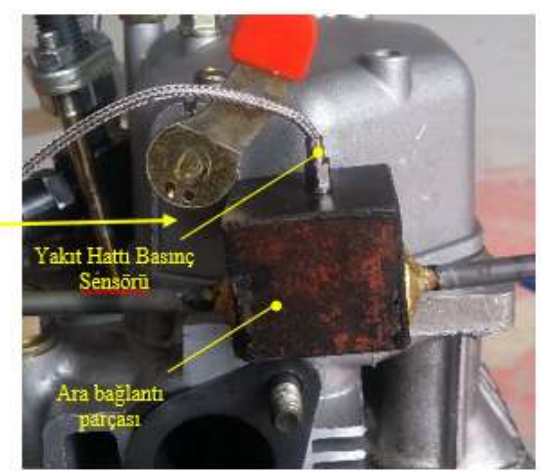

b) Yakıt hattı basınç sensörü ara bağlantı parçası

Şekil 3. Yakıt hattı basınç sensörü ara bağlantı parçasının yakıt hattı borusuna montajı. 


\subsection{Motor krank açısı ölçümü}

Motor krank mili dönüşünün derece olarak ölçülmesi amacıyla 50B model artımlı enkoder kullanılmıştır. Enkoderin özellikleri Tablo 4'de verilmiştir.

Tablo 4. Enkoder teknik özellikleri

\begin{tabular}{lcl}
\hline Model & & FNC 50B artımlı optik enkoder \\
\hline Besleme gerilimi & V DC & $4.75-30$ \\
Pulse hızı & (puls/devir) & 500 \\
Çıkışs sinyalleri & & $90^{\circ}$ kaymış A ve B, Z \\
Çalı̧ma sıcaklığı & ${ }^{\circ} \mathrm{C}$ & $-20-+85$ \\
Maksimum çalışma hızı & devir/dakika & 5000 \\
Mil yükü & $\mathrm{N}$ & $\leq 60$ eksenel \\
Frekans & $\mathrm{N}$ & $\leq 80$ radyal \\
\hline
\end{tabular}

Şekil 4'de artımlı enkoderin puls diyagramı görülmektedir. Şekilde görüldügü üzere, enkoder A, B ve $Z$ olmak üzere üç çıkışa sahiptir. Kanal B, Kanal A'yı 90 derece faz kayması ile yönlendirmektedir. Z kanalı, kodlayıcının her dönüşünde bir pulse oluşturmaktadır. A ve B kanalları dönüş yönü ve konum bilgisi için kullanılırken, Z kanalları devir sayısı ölçümü için kullanılmaktadır [18].

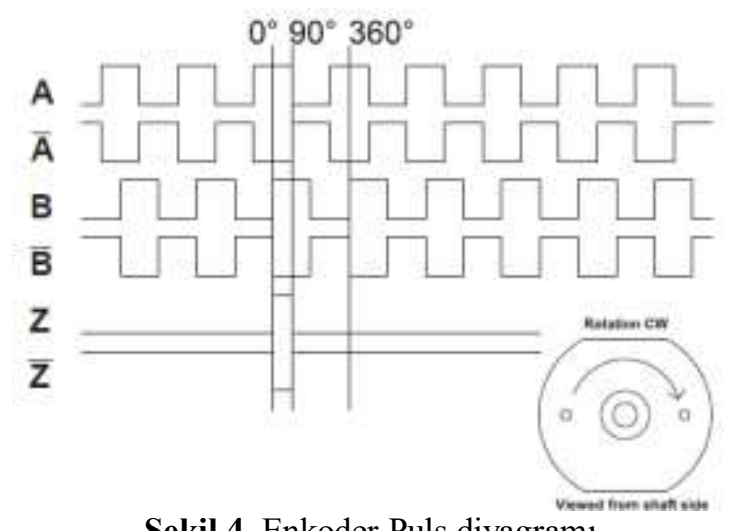

Şekil 4. Enkoder Puls diyagramı

Enkoder'in krank mili eksenine dik olarak bağlantısını gerçekleştirebilmek amacıyla krank kasnağı önüne 3 mm kalınlığındaki çelik sacdan destek parçası imal edilmiştir. Ayrıca enkoder ile krank milini aynı eksende bileştirerek krank milinin dairesel hareketini doğrudan enkodere iletmek amacıyla bağlantı parçası imal edilmiştir. Enkoderin $8 \mathrm{~mm}$ çapındaki mili ile bağlantı parçasının mili, bir kaplin yardımı ile aynı eksen üzerinde montajları gerçekleştirilmiştir. Enkoderin motor üzerinde montajı gerçekleştirilmiş hali Şekil 5'de görülmektedir. Literatürde, motor devrinin hassas bir şekilde ölçülmesi amacıyla çeşitli marka ve modellerde enkoderlerin yaygın olarak kullanılmakta olduğu görülmektedir [19-22].

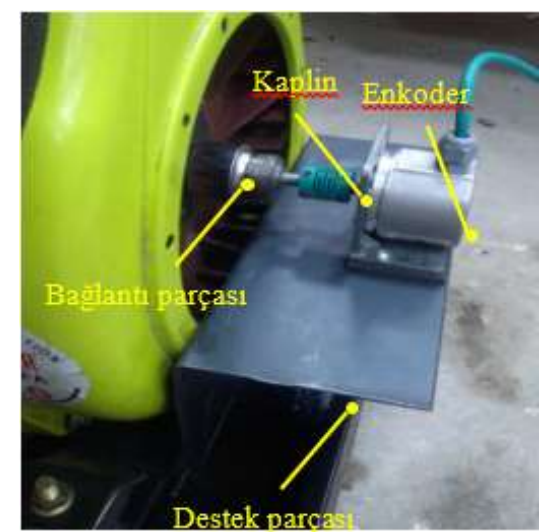

Şekil 5. Enkoderin motor üzerine montajı 


\subsection{Egzoz gazı sıcaklığının ölçülmesi}

Deney motorunun egzoz gazı sıcaklığının ölçülmesi işleminde bir K tipi termokupl kullanılmıştır. Literatürde benzer şekilde egzoz gazı sıcaklığının ölçülmesi işleminde K tipi thermokupl yaygın olarak kullanılmaktadır [23-26]. Egzoz borusu üzerine, motor çıkışından $20 \mathrm{~cm}$ ileriye K tipi termokupl yerleştirilmiş ve buradan egzoz gazı sıcaklıklarının ölçülmesi işlemi gerçekleştirilmektedir. Egzoz gazı sıcaklığının ölçülmesinde kullanılan K-tipi termokuplun deney düzeneğindeki montajı Şekil 6'da görülmektedir.

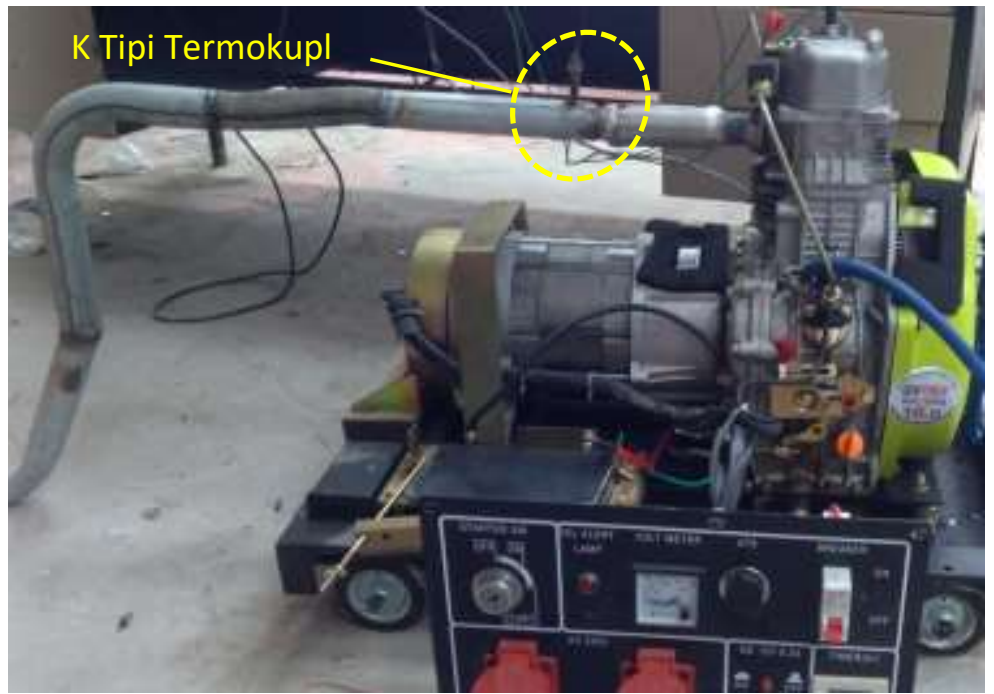

Şekil 6. Deney düzeneği üzerinde termokupl montajının gösterimi.

\subsection{Yakıt tüketim değerinin ölçülmesi}

İçten yanmalı motorlarda performans testlerinin gerçekleştirilmesi işlemlerinde, çalışma koşullarına göre motorun yakıt tüketiminin belirlenmesi oldukça önemlidir. Yakıt tüketimi değeri, belirli bir kütle ya da hacimdeki yakıtın tükenme süresi ile hesaplanabilmektedir [27-30].

Yapılan bu çalışmada da yakıt deposunun altına hassas bir terazi yerleştirilmiş, 10 gr yakıtın tükenmesi için geçen süre bir kronometre yardımı ile tespit edilmiştir. Daha sonra elde edilen bu değer kullanılarak saatteki yakıt tüketim değeri hesaplanmıştır. Çalışmada, 0,01 gram hassasiyete sahip RADWAG PS 6000.R2.H marka hassas terazi kullanılmıştır (Şekil 7).

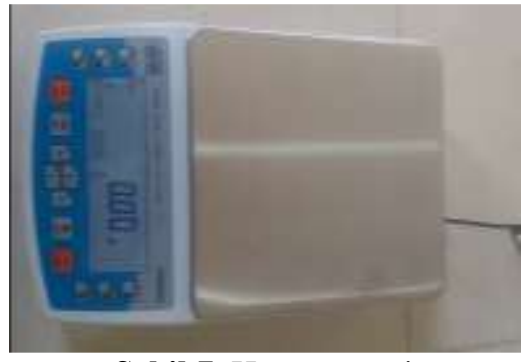

Şekil 7. Hassas terazi

\subsection{Motor test verilerinin kontrolü ve kaydedilmesi}

Yapılan çalışmada sabit hız jeneratörü kullanılmaktadır. Dolayısıyla, jeneratör motoru standart olarak dakikada 3000 devir dönecek şekilde ayarlanmıştır. Motor devri, jeneratör üzerinde bulunan elektronik hız kontrol devresi tarafından kontrol edilmektedir. 3000 devir/dakika (d/d) ile çalışmakta olan deney motorunun her bir krank açısı için veri kaydını gerçekleştirebilmek amacıyla yüksek örnekleme hızına sahip PicoScope marka 2406B Model 4 kanallı dijital osiloskop kullanılmıştır. Yapılan bu çalışmaya benzer şekilde, literatürde osiloskop kullanılarak veri kaydı işlemi gerçekleştirilen çalışmalara rastlamak 
mümkündür [31-34]. Şekil 8'de PicoScope marka 2406B Model 4 kanallı Osiloskop görülmektedir. Osiloskopun genel özellikleri Tablo 5’te verilmiştir.

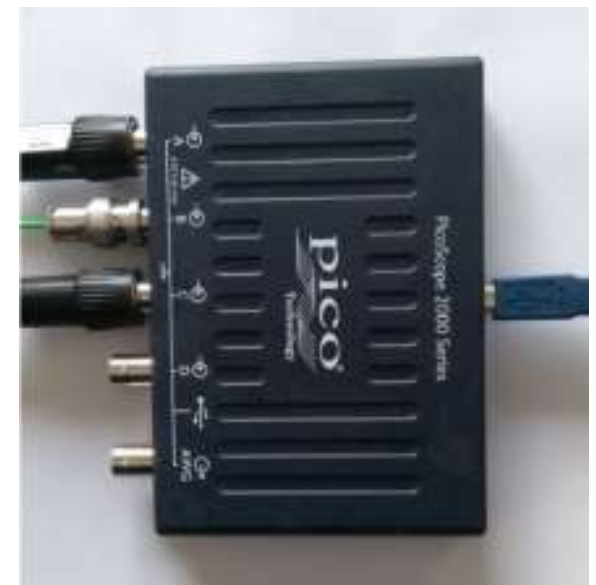

Şekil 8. PicoScope marka 2406B Model 4 kanallı Osiloskop.

Tablo. 5. PicoScope marka 2406B Model 4 kanallı Osiloskopun özellikleri.

\begin{tabular}{ll}
\hline Model & PicoScope 2406B dijital osiloskop \\
\hline Kanal sayıs1 & 4 channel \\
\hline Band genişliği & $50 \mathrm{MHz}$ \\
\hline Input ranges & $\pm 20 \mathrm{mV}- \pm 20 \mathrm{~V}$ \\
\hline Giriş̧ Hassasiyet & $4 \mathrm{mV} / \mathrm{div}-4 \mathrm{~V} / \mathrm{div}$ \\
\hline Giriş akım & $\mathrm{AC} / \mathrm{DC}$ \\
\hline DC doğruluğu & $\pm 3 \%( \pm 200 \mu \mathrm{V}$ tam değerinin $)$ \\
\hline Giriş konektörü & Tek uçlu, BNC (f) \\
\hline Maksimum örnekleme hızı & \\
$\begin{array}{l}\text { 1. Kanal } \\
\text { Kanal }\end{array}$ & $1 \mathrm{GS} / \mathrm{s}$ \\
3 ve 4 Kanal & $500 \mathrm{MS} / \mathrm{s}$ \\
\hline Eşdeğer zaman örnekleme oranı & $250 \mathrm{MS} / \mathrm{s}$ \\
\hline En kısa zaman tabanı & $10 \mathrm{GS} / \mathrm{s}$ \\
\hline En uzun zaman tabanı & $2 \mathrm{~ns} / \mathrm{div}$ \\
\hline
\end{tabular}

PicoScope osiloskopun yazılımı bilgisayara yüklendikten sonra bağlantı kablosu ile bilgisayara bağlanmaktadır. Elde edilen veriler osiloskop ara yüzü üzerinden bilgisayar ortamına aktarılmakta, kontrol ve kayıt işlemleri gerçekleştirilebilmektedir. Osiloskop ile elde edilen verilerin bilgisayar ekranında görüntüsü Şekil 9'da verilmiştir.

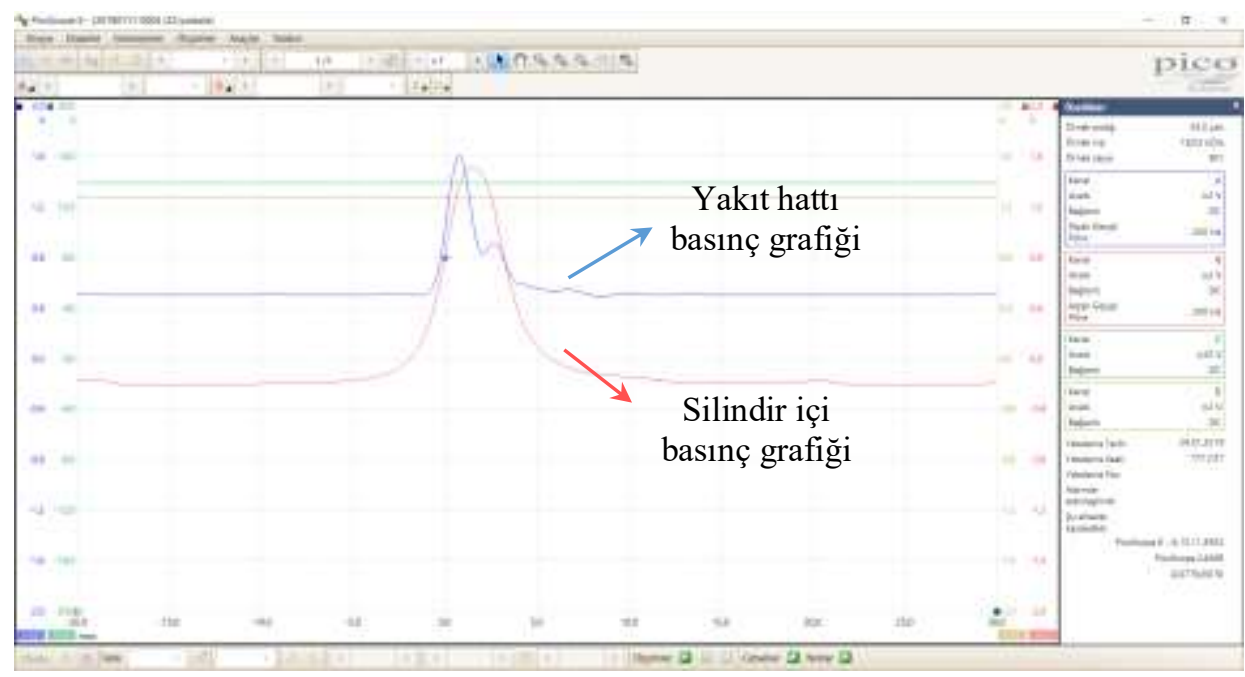

Şekil 9. Osiloskoptan elde edilen verilerin anlık görüntüsü. 
Kurulumu gerçekleştirilen ve deneysel çalışmaya hazır hale getirilen motor test ünitesinin genel görünümü Şekil 10’da verilmiştir.

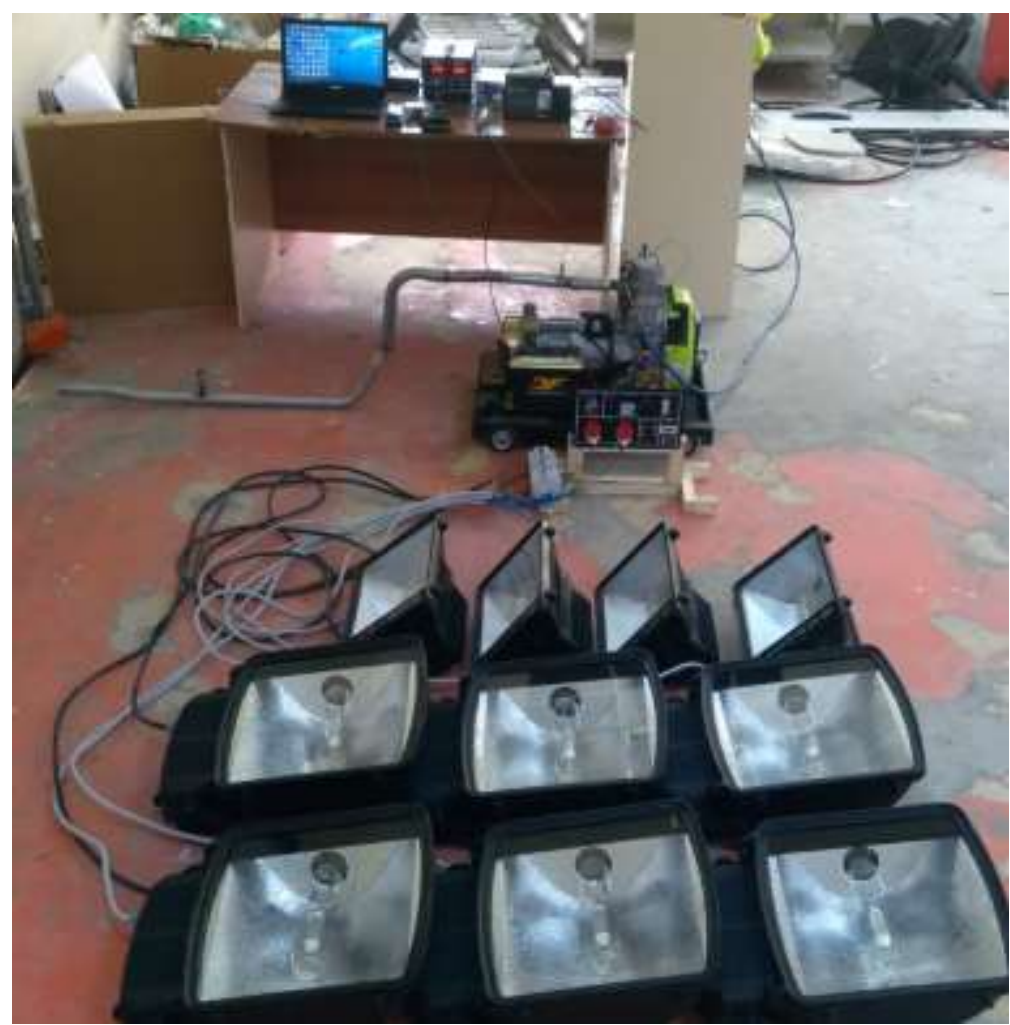

Şekil 10. Deney düzeneğinin genel görünümü

\section{3. Örnek uygulama}

Dizel jeneratörünün motor test ünitesine dönüştürülmesi aşamasından sonra, örnek bir uygulama gerçekleştirilmiştir. Uygulamada, dizel ve dizel+fuel-oil yakıt karışımlarının motor performansı üzerine etkileri incelenmiştir. Bu amaçla deneyler sabit motor devrinde $(3000 \mathrm{~d} / \mathrm{d})$, sabit motor yükünde (3500 W) gerçekleştirilmiştir.

Kurulan deney düzeneğinde fuel-oil yakıtının kullanılabilmesi için öncelikli olarak viskozite değerinin düşürülmesi gerekmektedir. Viskozitesi yüksek olan yakıtların dizel motorlarında kullanılması, motor performansı ve emisyonları açısından olumsuz sonuçlar doğurabilmektedir [35]. Bu amaçla iyi bir çözücü de olan toluen kimyasalından yararlanılmıştır. Fuel-oil yakıtının viskozite değerini düşürmek amacıyla içerisine $\% 2,5$ oranında toluen ilave edilmiştir. Toluenin fuel-oil içerisinde tamamen çözülmesini ve homojen bir karışım oluşumunu sağlanmak amacıyla, fuel-oil+toluen karışımları ağızı kapalı bir kap ile NÜVE marka çalkalamalı su banyosu cihazı içerisine yerleştirilmiş ve 1 saat boyunca çalkalanması sağlanmıştır. Deneysel çalışmada kullanılan fuel-oil+toluen karışımlarının bazı özellikleri Elazığ Valiliği Çevre Ölçüm Analiz Laboratuvarında analiz edilmiş ve Tablo 6'da verilmiştir.

Tablo 6. Deneysel çalışmada kullanılan yakıtlarının bazı özelliklere etkisi

\begin{tabular}{lccc}
\hline Yakıt & Isıl Değeri (cal/gr) & Viskozite $\left(\mathbf{m m}^{\mathbf{2}} / \mathbf{s}\right)$ & Yoğunluk $\left(\mathbf{g r} / \mathbf{c m}^{\mathbf{3}}\right)$ \\
\hline Dizel Yakıt1 ${ }^{[36]}$ & 10183 & 2,72 & 835 \\
Fuel-Oil & 10537 & 43,78 & 996 \\
Fuel-Oil+Toluen & 10337 & 24,56 & 963 \\
\hline
\end{tabular}

Elde edilen yeni karışım (fuel-oil+toluen) daha sonra dizel yakıtı içerisine kütlesel olarak \%5 ve $\% 10$ oranında ilave edilerek deney yakıtları elde edilmiştir. Dizel yakıtına ilave edilen yakıtların miktarları ve elde edilen karışımların isimleri Tablo 7'de verilmiştir. 
Tablo 7. Deneysel çalışmada kullanılan yakıt karışımları

\begin{tabular}{lccc}
\hline Yakıt & Toluen (Kütlece \%) & Fuel-Oil (Kütlece \%) & Dizel yakıtı (Kütlece \%) \\
\hline D100 & 0 & 0 & 100 \\
DTF5 & 2,5 & 5 & 95 \\
DTF10 & 2,5 & 10 & 90 \\
\hline
\end{tabular}

Yakıtsal özellikleri iyileştirilen fuel-oil yakıtının kütlesel olarak $\% 5$ ve $\% 10$ oranlarında dizel yakıtına karıştırılarak silindir içi basınç değişimi, maksimum silindir içi basınç değeri (Pmak), yakıt tüketimi ve egzoz gazı sıcaklığı incelenmiştir. Deney motoru sabit devir (3000 d/d) ve $3500 \mathrm{~W}$ güç üretecek şekilde yüklenmiş ve her bir yakıt için gerekli ölçümler tekrarlanmıştır.

İçten yanmalı bir motorda herhangi bir yakıtın yanması işlemini analiz edebilmek için gerekli olan en önemli parametre silindir içi gaz basıncının değişimidir [37]. Silindir içerisindeki yanmanın anlaşılabilmesi ve yakıt özelliklerinin (1sıl değer, yoğunluk, viskozite vb.) yanma üzerine etkisinin incelenebilmesi için silindir içerisindeki ve yakıt hattındaki basınç değişimlerinin ölçülerek kayıt altına alınması gerekmektedir. Silindir içi gaz basıncı, silindir içerisindeki mekanik yüklerin krank açısına göre yayılmasını ifade etmektedir [38]. Yanma sonucunda silindir içi basıncın her ne kadar aniden yükselmesi beklense de aşırı ani basınç yükselmeleri de çoğu kez motor parçalarına zarar veren vuruntuya sebep olabilmektedir. Dolayısıyla, silindir içi basıncının ölçülmesi ile maksimum silindir içi basıncının gerçekleştiği yer, maksimum basınç artış oranı, yanma başlangıcı, yanma sonu, yanma süresi gibi veriler elde edilerek kullanılan yakıtın yanma özellikleri hakkında değerlendirme yapılabilmektedir. Yapılan bu çalışmada, motorun krank mili açısının her bir derecesi için silindir içi basınç değişimleri ölçülerek elde edilen veriler grafik haline getirilmiştir.

Şekil 11'de dizel yakıtının içerisine fuel-oil+toluen ilavesinin kullanılması ile silindir içerisindeki değişim verilmektedir. Yine dizel yakıtı ile karıştırıldığında fuel-oil katkısı ile maksimum silindir içi basıncın düştüğü görülmüştür. Dizel yakıtının içerisine fuel-oil+toluen ilavesi ile birlikte yanmanın süresinin uzadığı görülmüştür. Dizel yakıtına Fuel-oil+toluen ilavesi ile karışımın setan sayısı azaltmakta ve tutuşma gecikmesi süresinde artış meydana gelmektedir. Bu durum silindir içindeki maksimum basınç artışını kısıtlamaktadır. Dizel motorlarında tutuşma gecikmesi süresinin istenilen süreden daha fazla olması istenilen bir durum değildir. Çünkü bu durumda yakıtın tutuşmaya başlaması, piston genişleme yönünde ilerlerken gerçekleşmekte, maksimum yanmanın oluştuğu evrede silindir içerisindeki hacmin artmış olması silindir içi basıncın azalmasına neden olmaktadır. Bu nedenle yanmanın gecikerek oluşması maksimum silindir içi basıncın azalmasına ve yakıttan elde edilen yararlı işin sınırlandırılmasına neden olmaktadır.

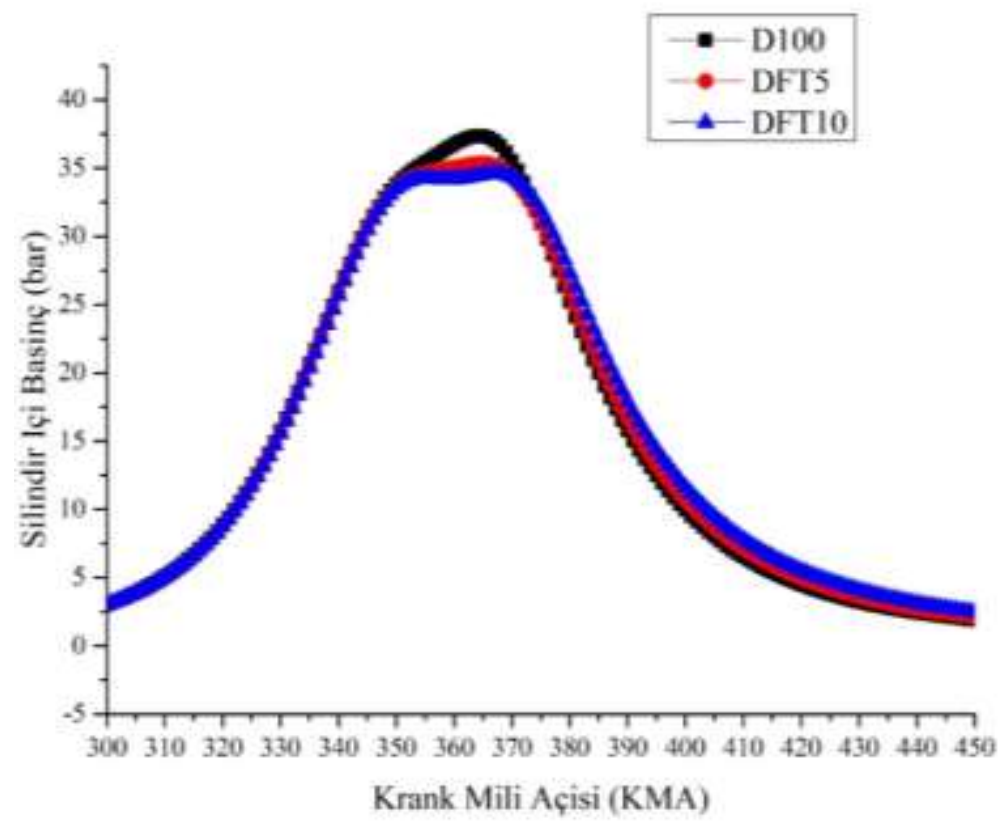

Şekil 11. Dizel Yakıtına fuel-oil+toluen ilavesinin silindir içi basınç değişimine etkisi 
Şekil 12'de Pmak değerinin dizel yakıtına ilave edilen fuel-oil+toluen ile değişimi verilmiştir. Dizel yakıtına fuel-oil+toluen ilavesi ile birlikte Pmak değerinin azaldığı görülmektedir. Yakıtın yüksek viskozitesi ve yoğunluğu, kötü enjeksiyon karakteristiklerine yol açmakta ve dolayısıyla zayıf yanmaya neden olmaktadır [37]. D100 yakıtı ile maksimum 37,35 bar basınç değeri elde edilirken, DFT5 yakıtı kullanımı ile 35,34 bar ve DFT10 yakıtı ile birlikte ise 34,62 bar değeri elde edilmiştir. Literatürde, yüksek viskozite ve yoğunluğa sahip yakıtlar ile ilgili yapılan çalışmalar incelendiğinde benzer sonuçların elde edildiği görülmüştür $[25,39,40]$.

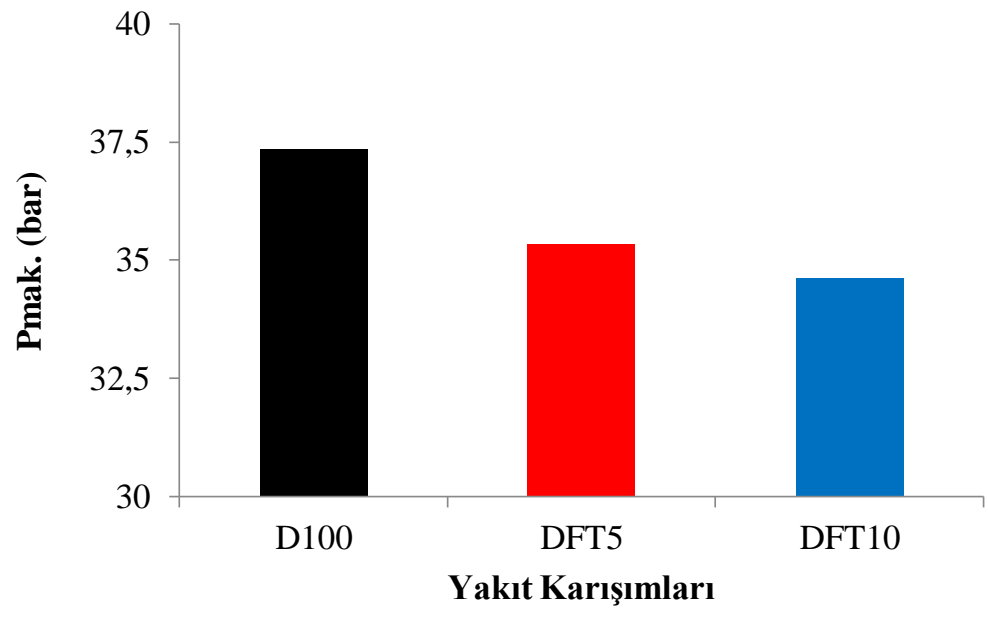

Şekil 12. Pmak'ın yakıt karışımlarına göre değişimi

Dizel yakıtına fuel-oil+toluen ilavesi ile yakıt tüketiminde meydana gelen değişim şekil 13'te gösterilmektedir. İçten yanmalı motorlarda motor performansının belirlenmesi işleminde önemli bir parametre olan yakıt tüketimi, verilen test koşulları altında belirli bir zaman içerisinde hacimsel veya kütlesel yakıt tüketiminin ölçülmesi ile belirlenebilmektedir [41]. Bu çalışmada yakıt tüketimi, 0,01 gram hassasiyete sahip terazi kullanılarak 10 gr yakıtın tükenmesi için geçen süre kaydedilerek hesaplanmıştır. Dizel yakıtına fuel-oil+toluen ilavesi ile yakıt tüketiminde artı̧̧ görülmüştür. Yapılan deneylerde yakıt tüketimi D100 yakıtı ile 1458,7 g/saat iken DFT5 yakıtının kullanımı ile 1470,26 $\mathrm{gr} / \mathrm{saat}$ ve DFT10 yakıtının kullanılması ile 1482,5 gr/saat olarak elde edilmiştir. Bir motorun yakıt tüketiminin yakıtın yoğunluğuna, viskozitesine, ısıl değerine, yakıt hava oranına ve motorun çalışma verimliliğine bağlı olarak değişebileceği ifade edilmektedir [41,42]. Daha önce yapılan çalışmalarda, genel olarak yüksek yoğunluk, viskozite değerlerine sahip yakıtların yakıt tüketimini arttığı görülmüştür [43-46].

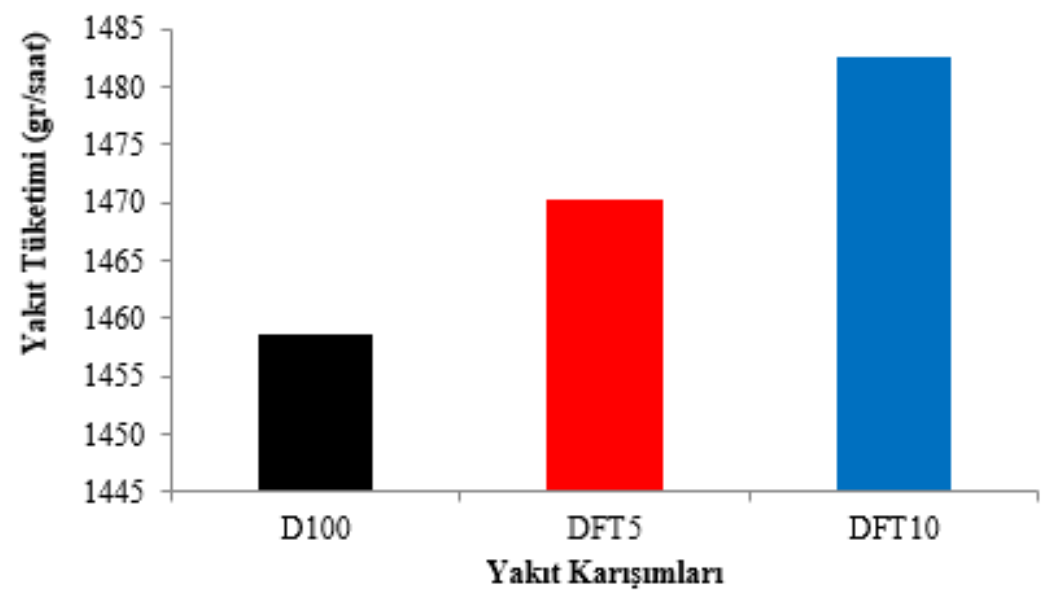

Şekil 13. Yakıt tüketiminin yakıt karışımlarına göre değişimi

Şekil 14'te egzoz gazı sıcaklığının dizel yakıtına ilave edilen fuel-oil+toluen ile değişimi gösterilmektedir. Dizel yakıtına fuel-oil+toluen ilavesi ile birlikte egzoz gazı sıcaklığında artış meydana 
gelmiştir. Dizel yakıtına fuel-oil+toluen ilavesi ile birlikte yanmanın uzadığı silindir içi basınç eğrilerinden görülmektedir (Şekil 11). Silindir içerisinde uzayan yanma işleminin genişleme zamanı sonlarına sarkması, egzoz gazı sıcaklığının artmasına neden olduğu düşünülmektedir.

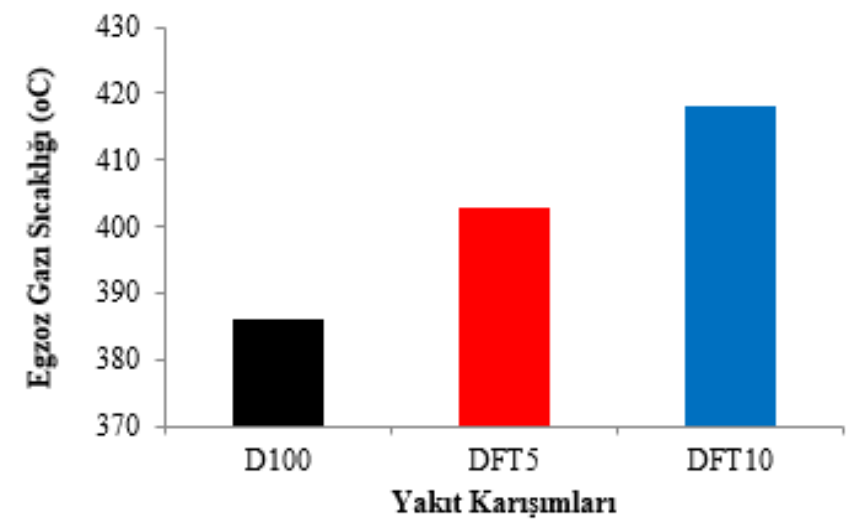

Şekil 14. Egzoz Gazı Sıcaklığının yakıt karışımlarına göre değişimi

\section{Sonuç ve Öneriler}

Günümüzde içten yanmalı motorların test edilmesi işleminde yaygın olarak motor dinamometreleri kullanılmaktadır. Motor dinamometreleri oldukça yüksek maliyetli cihazlardır ve genel olarak yurt dışından ithal yoluyla temin edilmektedirler. Yapılan bu çalışmada, bir dizel jeneratörünün düşük maliyetli motor test düzeneğine dönüştürülebileceği görülmüştür.

Dizel bir jeneratörde dizel yakıtının içerisine, fuel-oil+toluen ilavesi ile motor parçaları ve vuruntulu çalışma açısından olumsuz bir durum ile karşılaşılmamıștır. Motor performansı açısından bakıldığında ise silindir içi basınç değerinde dizel yakıtına göre DFT5 yakıtı ile \%5 ve DFT10 yakıtı ile \%7.3'lük bir azalma meydana gelmiştir. Bunun yanında saatlik yakıt tüketiminde ise DFT5 yakıtı ile \%1.2 ve DFT10 yakıtı ile \% 1.9'luk artış görülmüştür. Elde edilen motor test düzeneğinde dizel ve dizel+fuel-oil karışımları kullanılarak birtakım deneyler gerçekleştirilmiştir. Dizel yakıtına fuel-oil katkısı ile silindir içi basınç değerinin düştüğü, yakıt tüketiminin ve egzoz gazı sıcaklığının arttığı görülmüştür.

\section{Teșekkür}

Bu çalışma, BAP-17-MMF-4901-03 proje numarası ile Muş Alparslan Üniversitesi Bilimsel Araştırma Projeleri birimi tarafından desteklenmiştir.

\section{Yazarların Katkısı}

Çalışmada tüm yazarlar eşit oranda katkı sunmuştur.

\section{Çıkar Çatışması Beyanı}

Yazarlar arasında herhangi bir çıkar çatışması bulunmamaktadır.

\section{Araştırma ve Yayın Etiği Beyanı}

Yapılan çalışmada, araştırma ve yayın etiğine uyulmuştur.

\section{Kaynaklar}

[1] Passenbrunner T.E., Sassano M., Re L. 2013. Optimal Control of Internal Combustion Engine Test Benches equipped with Hydrodynamic Dynamometers. 7th IFAC Symposium on Advances in Automotive Control, September 4-7, pp576-581, Tokyo, Japan. 
[2] Blumenschein J., Schrangl P., Passenbrunner T.E., Trogmann H., Re L. 2013. Easily Adaptable Model of Test Benches for Internal Combustion Engines. 2013 European Control Conference (ECC), July 17-19, 2013, Zürich, Switzerland.

[3] Öz İ.H., Borat O., Sürmen A. 2003. İçten Yanmalı Motorlar. Birsen Yayınevi, İstanbul.

[4] Batmaz U. 2010. Construction of a computer controlled diesel engine setup for performance and emission test. Master of Science in Mechanical Engineering Department, Middle East Technical University, Ankara, Türkiye.

[5] Aktaş A., Aydın M., Sekmen P. 2016. Bir AC Jeneratörün Motor Dinamometresi Olarak Kullanılabilirliğinin Araştırılması. El-Cezeri Fen ve Mühendislik Dergisi, 3 (3): 498-505.

[6] Çelik M.B., Bayır R., Özdalyan B. 2007. Bilgisayar destekli motor test standının tasarımı ve imalatı. Teknoloji, 10 (2): 131-141.

[7] Koç T. 2012. Bir motor test ünitesinin kontrol sisteminin tasarımı, Yüksek Lisans Tezi, Sakarya Üniversitesi, Fen Bilimleri Enstitüsü, Sakarya.

[8] Oliveira A., Morais A.M., Valente O.S., Sodré J.R. 2014. Combustion, performance and emissions of a diesel power generator with direct injection of B7 and port injection of ethanol. $\mathrm{J}$ Braz. Soc. Mech. Sci. Eng., 39: 1087-1096.

[9] Işık M.Z., Bayındır H., İscan B., Aydın H. 2017. The effect of n-butanol additive on low load combustion, performance and emissions of biodiesel-diesel blend in a heavy duty diesel power generator. Journal of the Energy Institute, 90: 174-184.

[10] Lata D.B., Misra A., Medhekar S. 2012. Effect of Hydrogen and LPG Addition on the Efficiency and Emissions of a Dual Fuel Diesel Engine. International Journal of Hydrogen Energy, 37: 60846096.

[11] Singh R.N., Singh S.P., Pathak B.S. 2007. Investigations on Operation of CI Engine Using Producer Gas And Rice Bran Oil In Mixed Fuel Mode. Renewable Energy, 32: 1565-1580.

[12] Chung T.W., Liu K.T. Gao S. 2012. Fuel Properties and Emissions from a Diesel Power Generator Fuelled with Jatropha Oil and Diesel Fuel Blends. Advanced Materials Research, 347-353: 26882691.

[13] Killol A., Reddy N. Paruvada S., Murugan S. 2019. Experimental studies of a diesel engine run on biodiesel n-butanol blends. Renewable Energy, 135: 687-700.

[14] Wittek K., Geiger F., Andert J., Martins M., Cogo V., Lanzanova T. 2019. Experimental investigation of a variable compression ratio system applied to a gasoline passenger car engine. Energy Conversion and Management, 183: 753-763.

[15] Kumar M.S., Arul K., Sasikumar N. 2019. Impact of oxygen enrichment on the engine's performance, emission and combustion behavior of a biofuel based reactivity controlled compression ignition engine. Journal of the Energy Institute, 92: 51-61.

[16] Montoya J.P.G., Diaz G.J.A., Arrieta A.A.A. 2018. Effect of equivalence ratio on knocking tendency in spark ignition engines fueled with fuel blends of biogas, natural gas, propane and hydrogen. International Journal of Hydrogen Energy, 43: 23041-23049.

[17] Labeckas G., Slavinskas S. 2013. Performance and emission characteristics of a direct injection diesel engine operating on KDV synthetic diesel fuel. Energy Conversion and Management, 66: 173-188.

[18] Aydın M., Irgin A., Çelik M.B. 2018. The Impact of Diesel/LPG Dual Fuel on Performance and Emissions in a Single Cylinder Diesel Generator. Applied Sciences, 8 (5): 825, 1-14.

[19] Hawi M., Elwardany A., Ookawara S., Ahmed M. 2019. Effect of compression ratio on performance, combustion and emissions characteristics of compression ignition engine fueled with jojoba methyl ester. Renewable Energy, 141: 632-645.

[20] Karthickeyan V. 2019. Effect of combustion chamber bowl geometry modification on engine performance, combustion and emission characteristics of biodiesel fuelled diesel engine with its energy and exergy analysis. Energy, 176: 830-852.

[21] Luo Q., Hu J.B., Sun B., Liu F., Wang X., Li C., Bao L. 2019. Experimental investigation of combustion characteristics and NOx emission of a turbocharged hydrogen internal combustion engine. International Journal of Hydrogen Energy, 44: 5573-5584.

[22] Yeom J.K., Jung S.H., Yoon J.H. 2019. An experimental study on the application of oxygenated fuel to diesel engines. Fuel, 248: 262-277. 
[23] Öztürk U., Hazar H., Y1lmaz F. 2019. Comparative performance and emission characteristics of peanut seed oil methyl ester (PSME) on a thermal isolated diesel engine. Energy, 167: 260-268.

[24] Lee J., Park C., Kim Y., Choi Y., Bae J., Lim B. 2019. Effect of turbocharger on performance and thermal efficiency of hydrogen-fueled spark ignition engine. International Journal of Hydrogen Energy, 44: 4350-4360.

[25] Asokan M.A., Prabu S.S., Bade P.K.K., Nekkanti V.M., Gutta S.S.G., 2019. Performance, combustion and emission characteristics of juliflora biodiesel fuelled DI diesel engine. Energy, 173: 883-892.

[26] Nour M., El-Seesy A.I., Abdel-Rahman A.K., Bady, M. 2018. Influence of adding aluminum oxide nanoparticles to diesterol blends on the combustion and exhaust emission characteristics of a diesel engine. Experimental Thermal and Fluid Science, 98: 634-644.

[27] Al-Dawody M.F., Jazie A.A., Abbas H.A. 2019. Experimental and simulation study for the effect of waste cooking oil methyl ester blended with diesel fuel on the performance and emissions of diesel engine. Alexandria Engineering Journal, 58: 9-17.

[28] Alptekin E., Sanli H., Canakci M. 2019. Combustion and performance evaluation of a common rail DI diesel engine fueled with ethyl and methyl esters. Applied Thermal Engineering, 149: 180191.

[29] Öztürk E. 2015. Performance, emissions, combustion and injection characteristics of a diesel engine fuelled with canola oil-hazelnut soapstock biodiesel mixture. Fuel Processing Technology, 129: 183-191.

[30] Özer S. 2015. Pirina yağından fuzel yağı ile biyodizel üretimi ve dizel motor performans ve emisyonlarına etkisi. Doktora Tezi, Karabük Üniversitesi, Fen Bilimleri Enstitüsü, Karabük.

[31] Sandalc1 T., Işın Ö., Galata S., Karagöz Y., Güler İ. 2019. Effect of hythane enrichment on performance, emission and combustion characteristics of an CI engine. International Journal of Hydrogen Energy, 44: 3208-3220.

[32] Jamrozik A., Tutak W., Pyrc M., Gruca M., Kocisko M. 2018. Study on co-combustion of diesel fuel with oxygenated alcohols in a compression ignition dual-fuel engine. Fuel, 221: 329-345.

[33] Tangöz S., Kahraman N., Akansu S.O. 2017. The effect of hydrogen on the performance and emissions of an SI engine having a high compression ratio fuelled by compressed natural. International Journal of Hydrogen Energy, 42: 25766-25780.

[34] Sharma T.K. 2015. Performance and emission characteristics of the thermal barrier coated SI engine by adding argon inert gas to intake mixture. Journal of Advanced Research, 6: 819-826.

[35] Yılmaz E., Aksoy F. 2019. \%10 Balık Yağı Biyodizeli-\%90 Dizel Yakıt Karışımı İle Çalışan Direkt Enjeksiyonlu Bir Dizel Motorunda Yanma ve Performans Karakteristiklerinin İncelenmesi. Gazi Üniversitesi Fen Bilimleri Dergisi Part C: Tasarım ve Teknoloji, 7 (1): 12-24.

[36] Şimşek D., Çolak N.Y. 2019. Biyodizel/Propanol Yakıt Karışımlarının Dizel Motor Emisyonlarına Etkisinin İncelenmesi. El-Cezeri Fen ve Mühendislik Dergisi, 6 (1): 166-174.

[37] Kumar R., Gakkhar R.P. 2018. Influence of nozzle opening pressure on combustion, performance and emission analysis of waste cooking oil biodiesel fuelled diesel engine. Int. J. Renewable Energy Technology, 9 (1/2): 244-259.

[38] Aydogan H., Acaroglu M., Ozcelik A.E. 2018. Comparison of Performance and Combustion Characteristics of Methyl Ester and Ethanol Used In a Common Rail Diesel Engine. 4th International Conference On Environmental Science and Technology, 19-23 September 2018 Kiev, Ukraine.

[39] Kumar R., Gakkhar R.P. 2018. Influence of nozzle opening pressure on combustion, performance and emission analysis of waste cooking oil biodiesel fuelled diesel engine. Int. J. Renewable Energy Technology, 9 (1/2): 244-259.

[40] Azad A.K., Rasul M.G., Bhatt C. 2019. Combustion and emission analysis of Jajoba biodiesel to assess its suitability as an alternative to diesel fuel. Energy Procedia, 156: 159-165.

[41] Raman L.A., Deepanraj B., Rajakumar S., Sivasubramanian V. 2019. Experimental investigation on performance, combustion and emission analysis of a direct injection diesel engine fuelled with rapeseed oil biodiesel. Fuel, 246: 69-74.

[42] Srivastava P.K., Verma M. 2008. Methyl ester of karanja oil as an alternative renewable source energy. Fuel, 87: 1673-1677. 
[43] Arunkumar M., Kannan M., Murali G. 2019. Experimental studies on engine performance and emission characteristics using castor biodiesel as fuel in CI engine. Renewable Energy, 131: 737744.

[44] Dhanasekaran R., Ganesan S., Kumar B.R., Saravanan S. 2019. Utilization of waste cooking oil in a light-duty DI diesel engine for cleaner emissions using bio-derived propanol. Fuel, 235: 832837.

[45] Shen X., Shi J., Cao X., Zhang X., Zhang W., Wu H. 2018. Real-world exhaust emissions and fuel consumption for diesel vehicles fueled by waste cooking oil biodiesel blends. Atmospheric Environment, 191: 249-257.

[46] Valente O.S., Silva M.J., Pasa V.M.D., Belchior C.R.P., Sodre J.R. 2010. Fuel consumption and emissions from a diesel power generator fuelled with castor oil and soybean biodiesel. Fuel, 89: 3637-3642. 